\title{
小型合併処理浄化槽の嫌気ろ床における浮遊物捕捉と 有機物除去の特性評価
}

\author{
Removal Characteristics of Suspended Solids and Organic Compounds in Anaerobic Filter \\ Process of Small-Scale Domestic Wastewater Treatment Facilities (Gappei-shori johkasou)
}

\author{
小川 浩 ${ }^{*}$ 、岩堀恵祐 ${ }^{2}$ \\ ${ }^{1}$ (財)日本環境整備教育センター $=$ T130-0024 東京都墨田区菊川2丁目23-3 \\ 静岡県立大学環境科学研究所 $/ \bar{T} 422-8526$ 静岡市谷田52-1 \\ HIROSHI OGAWA ${ }^{1 *}$ and KEISUKE IWAHORI ${ }^{2}$ \\ ${ }^{1}$ Japan Education Center of Environmental Sanitation \\ 12-23-3, Kikukawa, Sumida-ku, Tokyo, 130-0024 Japan
}

${ }^{2}$ Institute for Environmental Sciences, University of Shizuoka/52-1, Yada, Shizuoka, 422-8526 Japan

\begin{abstract}
Domestic wastewater treatment facilities, being called 'Gappei-shori johkasou', play an important role in the wastewater countermeasures of Japan. In small-scale gappei-shori johkasous for less than 50 persons' use, anaerobic filter process has been usually adopted as a primary treatment. Removal characteristics of organic compounds in this process have been reported, but the greater part of these results cannot be applied to the operation of johkasous as a practical matter, because of using artificial wastewater in the laboratory work. In this paper,therefore experimental investigations were carried out to make clear the removal characteristics of suspended solids, in addition to organic compounds, in this process of the actual johkasous.

The results showed that high SS removal ratio was achieved when netlike plates filter medium with a dimension of $100 \mathrm{~mm} \times 70 \mathrm{~mm}$ and ball-like skeleton filter medium were used in the 1st chamber and 2nd chamber of anaerobic filter tank, respectively. The BOD removal rate in this tank can be expressed by a linear reaction. Compared to a sedimentation/ separation tank in which there is no filter medium, low molecule-ization of organic compounds in anaerobic filter tank progressed faster even though the HRT is threefifth of that in sedimentation/separation tank. Most of the VFA in anaerobic filter tank was found to be decomposed into acetic acid and propyonic acid.
\end{abstract}

Key words: small-scale domestic wastewater treatment facility (small-scale gappei-shori johkasou), anaerobic filter process, suspended solids, organic compounds, removal characteristics

\section{1. はじめに}

我が国で適用されている生活排水処理システムは、対 象となる排水の種類や施設の規模、処理対象区域、根拠
となる法令などの相違により、17種類に分類されてい る"。これらのシステムの中で、合併処理浄化槽はわが 国特有の処理システムであり、公共下水道とともに、生 活排水対策として重要な役割を担っている ${ }^{2)}$ 。特に、処

* Corresponding author 
理対象人員 50 人以下の小型合併処理浄化槽は、昭和 63 年 以後に急激に普及し、平成 11 年 3 月末現在で 932,076 基が 設置され ${ }^{31}$ 、下水道未整備地域の水環境保全に寄与して きた。

小型合併処理浄化槽の主要な処理方式には、平成12年 5 月 31 日の建設省（現国土交通省）告示第1465号 ${ }^{4}$ （以 下、構造方法と称す）で規定されている分離接触ばっ気 方式（告示第 1 の 1 ）、嫌気万床接触ばっ気方式（告示 第 1 の 2 )、脱窒ろ床接触ばっ気方式 (告示第 1 の 3 ) 及びその他の方式（告示第13）がある。しかし、その総 数の $92 \%$ に相当する 856,954 基が嫌気ろ床接触ばっ気方 式を採用している ${ }^{3 !}$ 。この方式は、1 次処理装直として 嫌気ろ床槽、2 次処理装置として接触ばっ気槽が用いら れているが、その他の方式でも 1 次処理装置に嫌気ろ床 槽あるいは嫌気ろ床槽と同等の単位装置が設けられてい る。このように、小型合併処理浄化槽のほとんどが、 1 次処理装置として嫌気ろ床を組み込んでいることがわか る。

嫌気ろ床槽内では、流入する浮遊物（SS）成分の捕捉 と、ろ材表面あるいはろ材間隙で増殖した嫌気性微生物 による有機物の分解が行われ、安定した処理条件では BOD 除去率 $80 \%$ 以上の性能が得られると報告されてい る5゙。しかし、多種多様のろ材が開発されているため、 その形状や充填方法により、槽内の水理学的特性や微生 物の付着・棲息状況が異なり、また微生物付着と污泥の
蓄積に伴う水理学的変化も槽内で生じやすい。使用ろ材 による水理学的・微生物学的な相違は、嫌気ろ床におけ る流入SSの捕捉性と有機物の除去特性に影譬を及ほす ことは経験的に知られているが、嫌気ろ床が 1 次処理と して認識されてきた経緯もあり、流入SSの捕捉性の観点 から検討を行った事例はほとんど報告されていない。さ らに、嫌気性ろ床の有機物除去特性は、主に人工下水を 用いた実験室レベルでの検討であり、実際に使用されて いる施設の特性は、必ずしも把握されてきたとは考えに くい。

そこで、本研究では、小型合併处理浄化槽の処理性能 に影響を及ほす嫌気ろ床に着目し、その合理的な設計と 維持管理に必要な知見を得ることを目的に、各種のろ材 によるSSの捕捉性と有機物の除去特性を実際の戸建住 宅に設置した小型合併処理浄化槽で検討した。

\section{2. 実験材料並びに方法}

\section{1 実験材料}

（1） 小型合併処理净化槽

Fig. 1 に示した小型合併処理净化槽（5人槽）を実験 に使用した。本実験の対象である嫌気ろ床槽の有効容量 は、 (1)SS 捕捉実験では第 1 室 $0.907 \mathrm{~m}^{3}$ 、第 2 室 $0.610 \mathrm{~m}^{3}$ の合計 $1.517 \mathrm{~m}^{3}$ 、(2)有機物除去実験では第 1 室 $1.023 \mathrm{~m}^{3}$ 、 第 2 室 $0.724 \mathrm{~m}^{3}$ の合計 $1.747 \mathrm{~m}^{3}$ である。

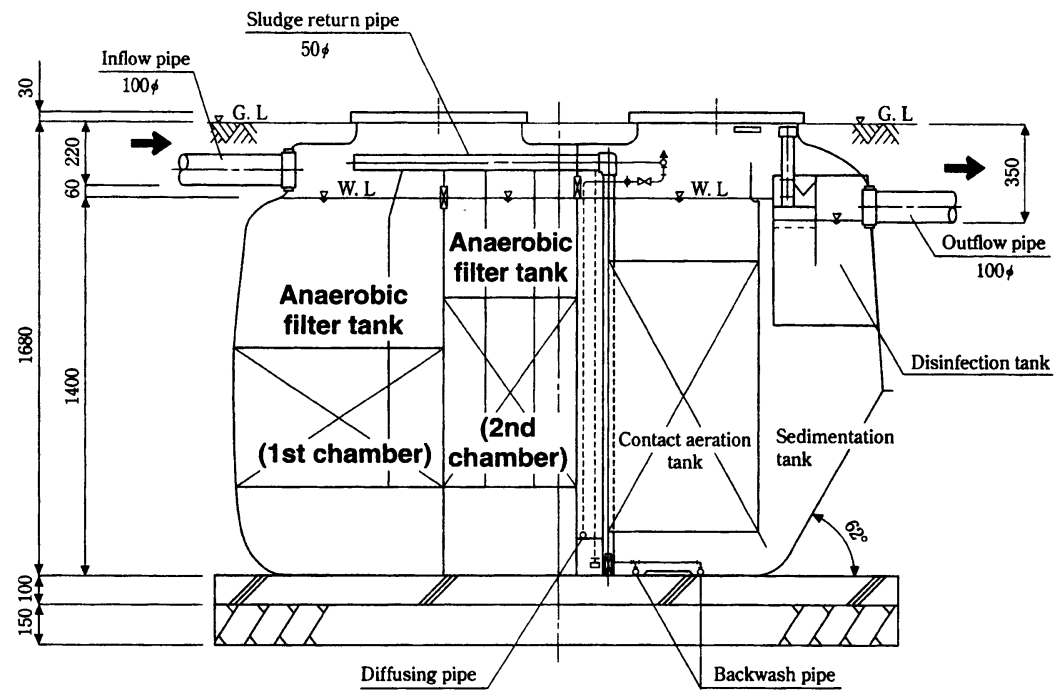

Fig. 1 Diagram of experimental equipment 


\section{（2）供試ろ材}

実験に供試したろ材は、Fig. 2 に示したように、網様 板状、骨格様球状、網様円筒状と板状の 4 種類であり、 その任様をTable 1 に一括表示した。これらのろ材を Table 2 に示した 4 種類の組み合わせで嫌気ろ床槽の第 1 室と第 2 室に充填した。なお、どのろ材も構造方法に
準拠して、第 1 室で40\%、第 2 室で60\%の充填率とし、 各RUNのろ材受けは第 1 室、第 2 室のいずれも槽底部か ら300mmの位置とした。また嫌気ろ床内に短絡水流の発 生を防止するため、万材の支持枠は、第 1 室及び第 2 室 のいずれも短絡防止用を兼ねた阻流板とした。
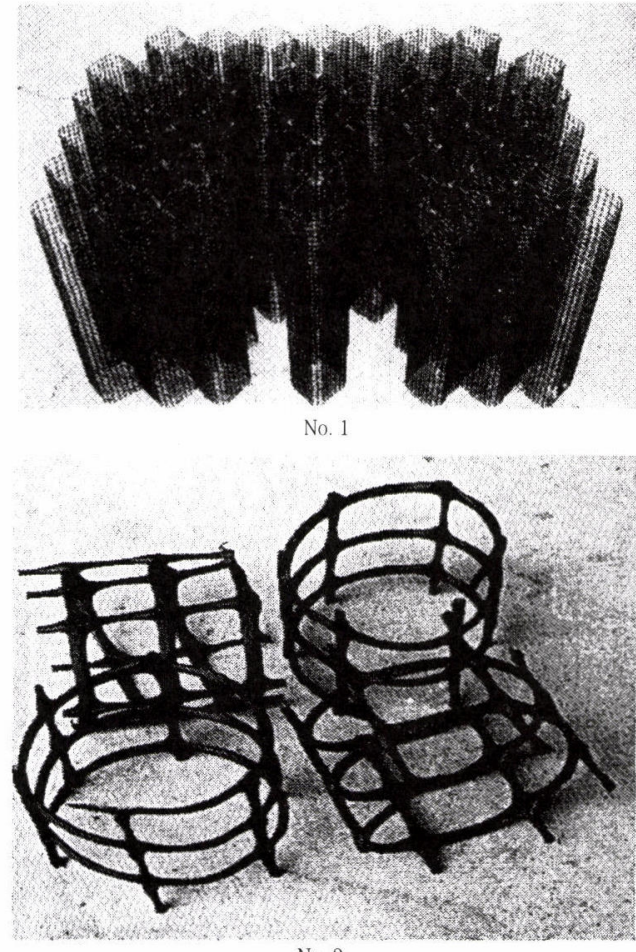

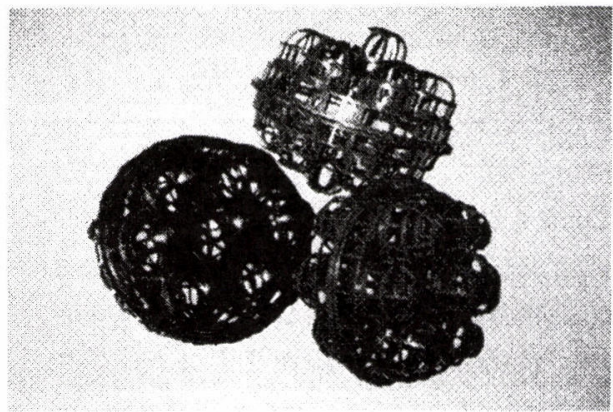

No. 2
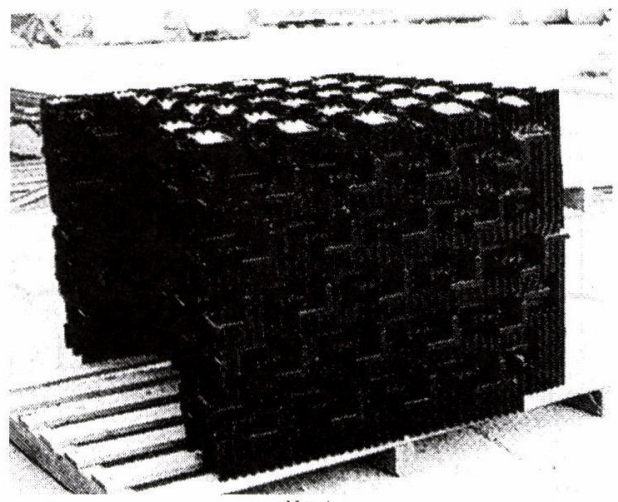

No. 4

Fig. 2 Constructin of contact medias

Table 1 Kinds of contact medias

\begin{tabular}{lcccc}
\hline & No. 1 & No. 2 & No. 3 & No. 4 \\
\hline shape & netlike plate & skelton global & netlike cylinder & plate \\
\hline pitch or size $(\mathrm{mm})$ & $100 \times 70$ & 150 & $75 \times 85$ & 80 \\
\hline specific surface area $\left(\mathrm{m}^{2} / \mathrm{m}^{3}\right)$ & 50 & 51 & 58 & 45 \\
\hline material & PE & PP & PE & PVC \\
\hline
\end{tabular}

Table 2 Experiment condition for contact medias in anaerobic filter

\begin{tabular}{llccc}
\hline & \multicolumn{1}{c}{ RUN1 } & RUN2 & RUN3 & RUN4 \\
\hline 1st chamber & No.1 (netlike plate) & No.2 (skelton global) & No.3 (netlike cylinder) & No.4 (plate) \\
\hline 2nd chamber & No.2 (skelton global) & No.2 (skelton global) & No.3 (netlike cylinder) & No.4 (plate) \\
\hline
\end{tabular}




\section{2 実験方法}

\section{(1) ろ材のSS捕捉実験}

流入水は、水道水 $200 l$ 当たりオカ $50.3 \mathrm{~kg}$ 及びトイレッ トペーパー25gを混合し、MLSS濃度を200〜250mg lに 調製したものを用いた。この流入水を 6 時30分から 20 時 30 分まで、嫌気ろ床槽第 1 室流入部に $60 l$ ，時で污水ポン プにより連続移送し、また浴槽排水を想定したピーク流 入量 $250 l$ 時を 7 時 30 分から 8 時 30 分の時間帯に移送す ることで、総流入水量として $1.0 \mathrm{~m}^{3}$ を供給した。なお、 本実験期間中、接触ばっ気槽から嫌気乃床槽第 1 室への 循環水は停止した。

試料は、嫌気ろ床槽第 1 室及び第 2 室の流出水 $1 l$ を 1 時間ごとに採取し、そのSS濃度を測定した。また実験柊 了時には、浄化槽本体の槽底部壁面に設けた点検公から、 嫌気ろ床槽のろ床内部及び底部の污泥堆皘状況を目視に より観察した。

\section{（2）嫌気ろ床における有機物除去実験}

大人 5 人が生活している戸建住宅に小型合併処理浄化 槽を新たに設置し、先のSS捕捉実験で良好な結果を示し たろ材を組み合わせて充填した。また嫌気性消化污泥 $(\mathrm{SS}$ 濃度 $10,000 \mathrm{mg} ， l$ ) $50 l$ を嫌気ろ床槽第 1 室に投入し、 接触ばっ気槽から嫌気ろ床槽第 1 室への循環比を 2.0 と して初期運転を開始した。

試料の採取は初期運転から 1 ケ月ごとに合計 6 回行い、 それぞれの試料採取日には嫌気ろ床槽第 1 室と第 2 室の 流出水を 1 時間ごとに採取し、承冷保存した。また流入 污水量は 1 時間ごとの水道使用量から算出し、さらに氷 冷保存した試料を流入污水量に比例した混合試料として

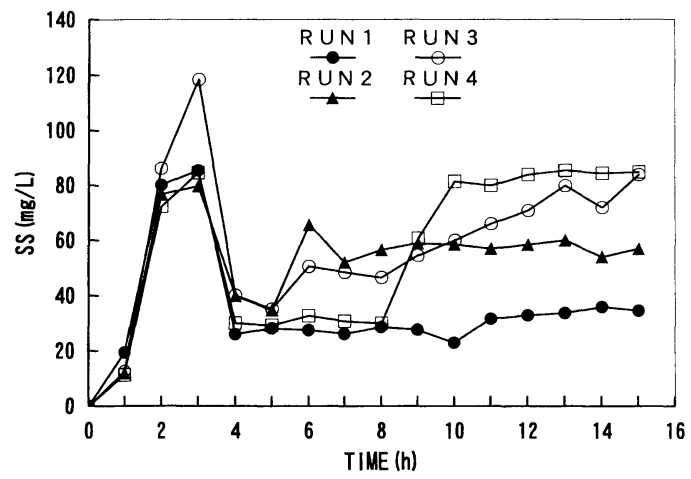

Fig. 3 SS variation in the 1 st chamber of anaerobic filter tank
から分析に供した。なお、比較対象実験として、別の戸 建住宅に設置され、嫌気ろ床を有しない沈殿分離槽を 1 次処理装置とした分離接触ばっ気方式（5 人槽）の小型 合併処理浄化槽でも同様の試料採取を行った。この沈殿 分離槽の有効容量は $2.600 \mathrm{~m}^{3}$ で、第 1 室は $1.600 \mathrm{~m}^{3}$ 、第 2 室 $1.000 \mathrm{~m}^{3}$ である。

\section{3 分析方法}

各実験とも、下水試験方法 ${ }^{61}$ に準拠して、試料の $\mathrm{pH}$ 、 $\mathrm{SS} 、$ 全 $\mathrm{BOD}_{5}$ (BOD) と溶解性 BOD $\mathrm{T}-\mathrm{N}$ 並びに揮発性低級脂肪酸を判定した。揮発性低級脂 肪酸は、試料を $1 \mathrm{~N}$ の $\mathrm{NaOH} て ゙ \mathrm{pH} 11$ に調整後、ホットフ レート上で $50 \mathrm{ml}$ 以下になるように混縮し、冷却後、GF Bのろ紙でろ過してから分析に供した。ろ液を（1+1) $\mathrm{H}_{2} \mathrm{SO}_{4}$ でpH $3 \sim 4$ に調整後、酢酸、プロピオン酸、酪 酸、吉草酸とカプロン酸の各濃度を $\mathrm{GC}$ (島津製作所製 $\mathrm{GC}$ -7A型）で測定した。GCの設定条件は、検出器FID、カ ラムPEG6000 ・径 $3 \mathrm{~mm}$ 及び長さ2.0mのステンレス製、

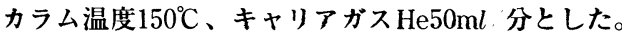

\section{3. 実験結果及び考察}

\section{1 万材のSS捕捉特性}

(1) 捕捉SS と流出SS

MLSS 濃度200〜 250mg $l$ に調製した流入水を所定の条 件で実験槽へ移送し、1 時間ごとに採取した嫌気ろ床槽 第 1 室流出水及び第 2 室流出水のSS濃度を Fig. 3 及び Fig. 4に示す。

嫌気ろ床槽第 1 室流出水のSS濃度は、 $250 l$ 時のピー ク流入時において、いずれのRUNも急激な上昇を示した。

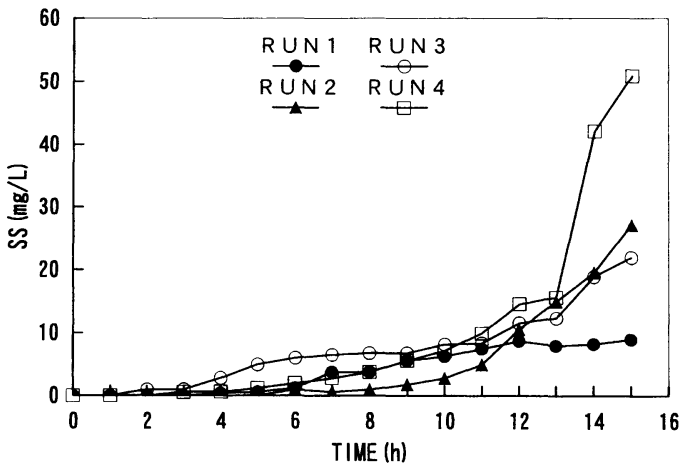

Fig. 4 SS variation in the 2 nd chamber of anaerobic filter tank 
その後、RUN 1 では、ピーク終了後 1 時間を経過すると SS濃度は低下し、23.0〜36.0mg lを維持した。RUN 4 では、RUN 1 と同様、ピーク終了 1 時間後において 30.0 $\mathrm{mg} / \mathrm{l}$ まで低下したが、 8 時間後から再び上昇し、ピーク 時と同程度の $85.0 \mathrm{mg} l$ に達した。この要因は、一度捕捉 されたSSのはく離を生じたか、あるいは短絡水流の形成 によるものと考えられる。

RUN 3 では、 4 種類の組み合わせの中でピーク時の $\mathrm{SS}$ 濃度が118.5mg lの最高值を示し、ピーク終了直後は 低下したが、その後、徐々に上昇し、SSの流出が認めら れた。

RUN 2 のピーク前後は、RUN 3 及び 4 と同様の傾向で あったが、 6 時間経過後は、54.0〜65. $5 \mathrm{mg} （$ の範囲で 推移した。

この流入条件での最大流入水量を時間平均流入水量で

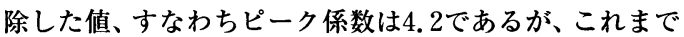
の小型合併処理浄化槽に係る実態調査報告 ${ }^{7,8)}$ において も1.2 15.2の範囲で、平均值5.5であり、本実験で与え たピーク特性は、通常の小型合併処理浄化槽と同程度で あった。流入SS濃度については、生活排水中の平均 SS 濃度250mg $l^{2}$ に近似した200〜250mg lで連続的に流入 させたため、通常の流入条件よりも高負荷であった。

一方、嫌気ろ床槽第 2 室流出水は、いずれのRUNも流 入開始 3 時間後からSSの流出が生じ、RUN 1 では10mg l以下を維持したが、RUN 2 4 4 については、11時間後 から上昇する傾向が認められ、特にRUN 4 では51mg $l$ ま で上昇した。これまで、嫌気ろ床槽流出水については、 スポット採水による測定值や日間平均值で評価されてい ることがほとんどであったが、各時間ごとのSSでは、Fig. 3 で示した著しい変動を生じていることが明らかであ り、250l 時のピーク時にはいずれのろ材の組み合わせ もSSの捕捉性が低下した。

嫌気ろ床槽の重要な役割はろ材及びろ床の SS捕捉性 であり、またろ材の仕様、充填方法、槽の有効水深がSS の捕捉性に影響することが報告されている 実験槽は、支持枠を兼ねた短絡防止用阻流板を槽壁面及 び隔壁面の全周にわたって設けているため、ピーク時以 外の流入条件では、短絡水流の形成は少ない。したがっ て、浴槽排水の流入状況を設定したピーク水量 $250 l /$ 時の 条件では、SSの流出を伴うため、流量調整機能を付加す ることで嫌気ろ床槽のSS保持能力はさらに向上すると 考えられる。

\section{（2）槽底部污泥の堆積量}

SSの捕捉性が最も良好な状況を示したRUN 1 につい て、実験終了後、躯体の壁面に設けられた点検空から内 部のSS堆積状況を確認した。Fig. 5で明らかなように、 第 1 室ではろ材充填部の下部付近及び槽底部に、また第 2 室ではろ材充填部にSSの堆積が多く認められた。

嫌気乃床槽では、ろ材の形状、充填方法、充填位置及 び流水方向などが污泥の蓄積と密接な関係があると報告 されている"11。RUN 1 では流入した污水が第 1 室のろ床 上部から下部へ下向流として流下する構造となっている が、ろ材充填部の下部及び槽底部にSSの堆積が認められ、 槽底部とろ材受け部までのろ材未充填部分もSSの貯留 能力を有していると判断された。第 2 室においては、ろ 材充填部にSSの堆積が多く認められ、またFig. 4より流 出水の SSが10mg $l$ 以下であることから、第 1 室流出水 のろ床下部から上部への上向流において、ろ材によるSS の捕捉が良好に機能していたと考えられる。

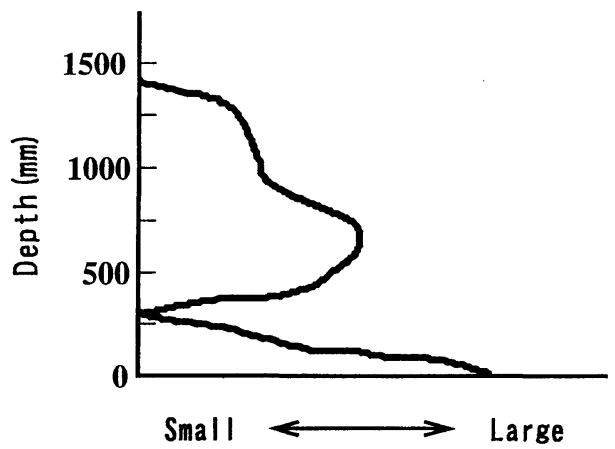

Sludge accumulation in the 1 st chamber

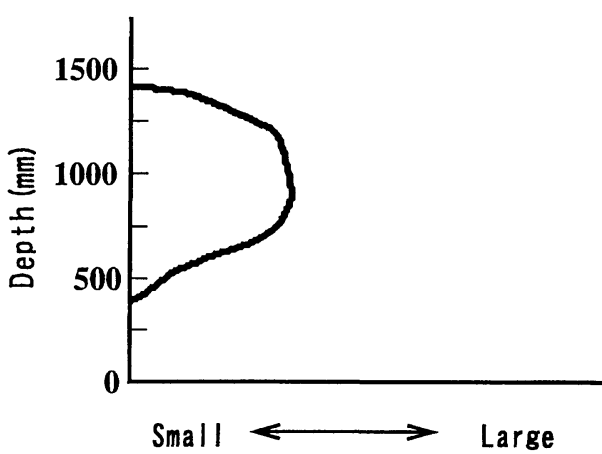

Sludge accumulation in the 2 nd chamber

Fig. 5 Sludge accumulation in the anaerobic filter tank 
したがって、本実験から、RUN 1 すなわち第 1 室にピ ッチ $100 \mathrm{~mm} \times 70 \mathrm{~mm}$ の網様板状ろ材を、また第 2 室に直 径 $150 \mathrm{~mm}$ の骨格様球状ろ材をそれぞれ充填する組み合 わせが、最もSS捕捉性の高い条件であることが明らかと なった。

\section{2 嫌気乃床の有機物除去特性}

\section{（1）流入条件と処理水質}

先のSS捕捉実験から、嫌気ろ床充填ろ材として第 1 室 網様板状ろ材及び第 2 室骨格様球状ろ材の組み合わせが 良好なSS捕捉性を示したので、本実験では同一のろ材を 充填した施設を対象とした。

実験対象施設の調査期間 6 ケ月間における流入水量 (水道使用量) は、平均 $1.16 \mathrm{~m}^{3}$ 日 (最小 1.02 最大 $1.29 \mathrm{~m}^{3}$

日）であり、設計水量 $1.0 \mathrm{~m}^{3}$ 日に近似した流入条件で あった。この日平均流入水量から嫌気ろ床槽の滞留時間 を計算すると、第 1 室 0.88 日、第 2 室 0.62 日、嫌気ろ床 槽全体として 1.51 日となる。実験期間中の時間最大流入 水量は $350 l$ 時で、ピーク時の滞留時間は平均滞留時間の 215 に相当する 4.8 時間であった。現在、小型合併処理 浄化槽の $92 \%$ は実験対象施設と同様に流量調整機能が 付加されていない構造であり ${ }^{3)}$ 、また過去の調查 ${ }^{7)}$ で、 ピーク時に 1 日の総流入水量の $30 \sim 40 \%$ が流入している 現状から、本施設は実験対象施設として代表的な流入条 件であったと判断できる。なお、比較対象実験で使用し た施設の流入水量は平均 $1.07 \mathrm{~m}^{3}$. 日（最小 0.91 最大 $1.18 \mathrm{~m}^{3}$ 日）であり、実験対象施設と同様の流入条件で あった。

嫌気ろ床槽及び沈殿分離槽の流出水質をTable 3 に示 す。嫌気ろ床槽流出水は、調查期間中、 $\mathrm{pH} 7.0 \sim 7.9$ 、 SS21. 4 42. 0mg $l$ 、BOD37 91mg $l 、$ D-BOD26 $60 \mathrm{mg}$ $l 、 \mathrm{~T}-\mathrm{N} 23.9$ - 46.8mg lであった。また沈殿分離槽流出
水はpH7.6〜7.9、SS36.4〜50.8mg $l 、 B O D 88 \sim 115 \mathrm{mg}$ $l 、 \mathrm{D}-\mathrm{BOD} 26 \sim 40 \mathrm{mg} l 、 \mathrm{~T}-\mathrm{N} 36.4 \sim 50.3 \mathrm{mg}$ l lであった。 実験対象施設は、流入管が嫌気ろ床槽流入部に直結し ているため、流入水を採取することが困難であったので、 著者ら ${ }^{12}{ }^{13)}$ が過去に調査した戸建住宅団地のコミュニテ イ・プラントの流入水質すなわち SS203mg/l、BOD 187 $\mathrm{mg} l$ を流入水質と仮定して、それぞれの平均除去率を求 めると、嫌気ろ床槽はSSが85.3\% (79.3〜89.5\%)、BOD が67.9\% (51.3〜80.2\%)、沈殿分離槽ではSSが78.1\% (75.0〜82.1\%)、BODが47.1\% (38.5〜52.9\%) となり、 嫌気ろ床槽の方が嫌気ろ床を有しない沈殿分離槽に比較 してSS及びBODのいずれの除去率も高い結果であった。

各槽の有効容量から設計上の滞留時間を比較すると、 沈殿分離槽は嫌気ろ床槽の 1.5 倍に相当する2.6日分で、 SS 除去率は同程度であったが、BOD除去率は嫌気ろ床槽 の方が高い傾向にあった。すなわち、嫌気ろ床槽では、 SSの捕捉とともにろ床内に付着した生物膜による BOD 除去効果が発揮されていたと考えられ、また沈殿分離槽 の滞留時間2.43日に対して嫌気ろ床槽は1.51日であり、 沈殿分離槽の有効容量の $62 \%$ あるあが、ろ材によるSSの 捕捉で有機物除去率 $60 \%$ 以上が期待できると推定される。

\section{（2）嫌気ろ床におけるBOD除去}

嫌気ろ床槽は、流入水中のSSを分離・眝留、ろ材に生 育固定した嫌気性細菌の作用により、有機物を分解し、 BODの低減と污泥の減量化を図ることを主たる目的と している ${ }^{14)}$ 。流出水のD - BOD BODを比較すると、Table 3 で明らかなように、嫌気ろ床槽では $0.45 \sim 0.73 に$ 対し て、沈殿分離槽は0.23〜0.38となり、SSの除去及び可溶 化が有機物除去に大きく寄与していたと推察される。

そこで、嫌気ろ床槽を第 1 室と第 2 室に区別せずに同 一の槽と考え、Fig. 6 のようなモデルを想定する。先に

Table 3 Effluents from 2nd chamber of anaerobic filter tank and 2nd chamber of sedimentation/ separation tank

\begin{tabular}{lcccc}
\hline \multirow{2}{*}{ Item } & \multicolumn{2}{c}{ Anaerobic filter tank effluent } & \multicolumn{2}{c}{ Sedimentation/separation tank effluent } \\
\cline { 2 - 5 } & Average & Range & Average & Range \\
\hline Temperature $\left({ }^{\circ} \mathrm{C}\right)$ & 20.4 & $9 \sim 28$ & 21.4 & $10 \sim 27$ \\
\hline $\mathrm{pH}$ & 7.4 & $7.0 \sim 7.9$ & 7.8 & $7.6 \sim 7.9$ \\
\hline $\mathrm{SS}(\mathrm{mg} / \mathrm{l})$ & 29.9 & $21.4 \sim 42.0$ & 44.4 & $36.4 \sim 50.8$ \\
\hline $\mathrm{BOD}(\mathrm{mg} / l)$ & 60.0 & $37 \sim 91$ & 99.0 & $88 \sim 115$ \\
\hline $\mathrm{D}-\mathrm{BOD}(\mathrm{mg} / l)$ & 41.0 & $26 \sim 66$ & 31.0 & $26 \sim 40$ \\
\hline $\mathrm{COD}(\mathrm{mg} / l)$ & 44.2 & $33.1 \sim 58.7$ & 46.7 & $53.3 \sim 60.0$ \\
\hline $\mathrm{T}-\mathrm{N}(\mathrm{mg} / l)$ & 34.2 & $23.9 \sim 46.8$ & 37.3 & $36.4 \sim 50.3$ \\
\hline $\mathrm{D}-\mathrm{BOD} / \mathrm{BOD}$ & 0.63 & $0.45 \sim 0.73$ & 0.31 & $0.23 \sim 0.38$ \\
\hline
\end{tabular}




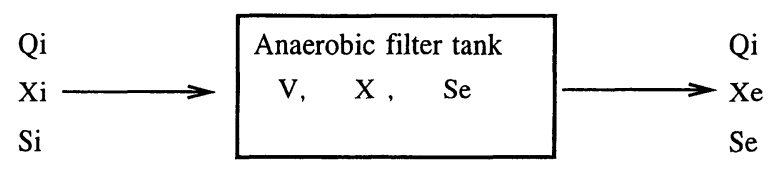

Qi:Inflow $\left(\mathrm{m}^{3} / \mathrm{hr}\right)$, Si:BOD in the influents of anaerobic filter $\operatorname{tank}(\mathrm{mg} / \mathrm{L}), \mathrm{Xi}: \mathrm{SS}$ in the influents of anaerobic filter $\operatorname{tank}(\mathrm{mg} / \mathrm{L}), \mathrm{V}:$ Effective volumes of anaerobic filter $\operatorname{tank}\left(\mathrm{m}^{3}\right), \mathrm{X}$ :Sludge concentrations in anaerobic filter $\operatorname{tank}(\mathrm{mg} / \mathrm{L})$, $\mathrm{Se}: B O D$ in the effluents of anaerobic filter $\operatorname{tank}(\mathrm{mg} / \mathrm{L}), \mathrm{Xe}: \mathrm{SS}$ in the effluents of anaerobic filter $\operatorname{tank}(\mathrm{mg} / \mathrm{L})$

Fig. 6 Model of anaerobic filter tank

述べたように、この槽内では微生物によるBODの除去と SS成分の可溶化によるBODの生成が同時に進行してい るので、流出BOD濃度は両者が加味されたものと捉える ことができる。そこで、Fig. 6より、BODの物質収支を とると次式が得られる。

$$
\mathrm{V}\left(\frac{\mathrm{dSe}}{\mathrm{dt}}\right)_{\mathrm{V}}=\mathrm{Qi} \cdot \mathrm{Si}-\mathrm{Qi} \cdot \mathrm{Se}-\mathrm{V} \cdot \frac{\mathrm{dSr}}{\mathrm{dt}}
$$

ここで、 $\left(\mathrm{dSe}, \mathrm{dt}^{\mathrm{d}}\right) \mathrm{v}$ はBOD濃度の時間変化 $(\mathrm{mg} / \mathrm{l} \cdot \mathrm{hr}) 、$ $\mathrm{Sr}$ は見かけのBOD除去濃度 $(\mathrm{Si}-\mathrm{Se}(\mathrm{mg} / l)) 、 \mathrm{dSr} / \mathrm{dt}$ は 見かけのBOD除去速度 $(\mathrm{mg} / l \cdot \mathrm{hr})$ である。

嫌気乃床槽内の微生物濃度 $(\mathrm{mg} / \mathrm{l})$ をとすると、式 (1)より、見かけの比BOD除去速度は次式で示される。

$$
\frac{1}{X} \frac{\mathrm{dSr}}{\mathrm{dt}}=\frac{\mathrm{Qi}(\mathrm{Si}-\mathrm{Se})}{\mathrm{X} \cdot \mathrm{V}}-\frac{1}{\mathrm{X}}\left(\frac{\mathrm{dSe}}{\mathrm{dt}}\right)_{\mathrm{V}}
$$

稲森ら ${ }^{15}$ は、流入SS成分を考虑していないベンチスケ 一ル規模の実験から、嫌気ろ床における比BOD除去速度 は一次反応式で表されると報告している。この知見を適 用すると、見かけの比BOD除去速度は次式で表される。

$$
\frac{1}{\mathrm{X}} \frac{\mathrm{dSr}}{\mathrm{dt}}=\mathrm{k} \cdot \mathrm{Se}
$$

なお、 $\mathrm{k}$ は一次反応速度恒数 $(l / \mathrm{mg} \cdot \mathrm{hr})$ であり、式 (2)の右辺を算出し、Seとともに図中にプロットすれば速 度恒数 $\mathrm{k}$ 求めることができる。しかし、式(2)の右辺に はBOD濃度の時間変化である $(\mathrm{dSe} / \mathrm{dt}) \mathrm{v}$ と、測定の困 難な微生物濃度Xが含まれているため、式(2)の右辺を容 易に算出できない。そこで、嫌気ろ床槽が一定の処理性 能を維持し、流入BOD濃度に大きな変動がなければ、微 生物濃度Xは一定であると仮定して、式(3)を皘分すると、 次式が得られる。

$$
-\ln \frac{\mathrm{Se}}{\mathrm{Si}}=\mathrm{k} \cdot \mathrm{X} \cdot \mathrm{t}
$$

ここで、 $\mathrm{t}$ は嫌気ろ床槽の水理学的㴖留時間 $(\mathrm{hr})$ であ る。

本実験で得られた結果を、式(4)にしたがって図中にフ ロットすると、Fig. 7 が得られた。本図より、滞留時間 tの増加とともに一 $\ln (\mathrm{Se} / \mathrm{Si})$ も増加して、両者の間に高 い相関関係 $\left(\mathrm{r}^{2}=0.823\right)$ のあることが明らかで、 $\mathrm{k} \cdot \mathrm{X}$ の値として0.052 (1/hr) が算出された。実験期間中、 槽内水温は $9 \sim 28^{\circ} \mathrm{C}$ と大きく変化した。この水温の変化 はk值に影響を及ほし、低水温ほど微生物の代謝活性 (即 ちk值）は小さくなると報告されている(5)。しかし、流入 SS成分が加味された本実験では、その可溶化が低水温ほ ど小さくなり、MLSS評価のXが高い值を維持したこと で、 $\mathrm{k} \cdot \mathrm{X} か ゙ 一$ 定值となったものと推察される。また流入 水の定量移送と $27.3 \sim 27.5^{\circ} \mathrm{C}$ の水温条件で実施設の嫌気 ろ床を検討した山本ら ${ }^{16)}$ は、経験則から $\mathrm{k} \cdot \mathrm{X}$ の值が $0.0464(1 / \mathrm{hr})$ であると報告している。ろ材の仕様や 流入水の性状、運転方法は異なるが、本実験とほほ同程 度の值が得られている。したがって、実際的な立場から、

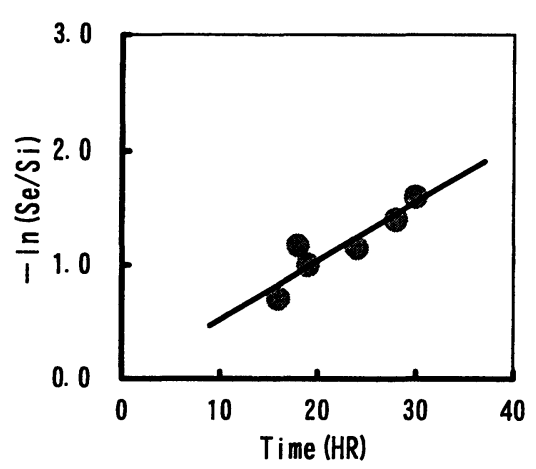

Fig. 7 Residual BOD rate vs. Time 
実施設の嫌気ろ床における見かけのBOD除去速度が一 次反応式にしたがうと捉えて差し支えないと思われる。 ただし、稲森ら ${ }^{15)}$ も指摘しているように、 $20^{\circ} \mathrm{C}$ から $30^{\circ} \mathrm{C}$ 付近を境にして嫌気性微生物の代謝活性が変化するため、 本実験の温度範用では一次反応式を適用することが望ま しい。なお、Fig.7から明らかなように、本実験ではBOD 除去反応に遅れ時間（Lag time）が認められなかった。 これは、実験開始前に嫌気性消化污泥を種污泥として投 入し、ろ材に微生物が十分に捕捉されていた結果と推察 され、嫌気ろ床槽の初期運転に重要な示唆を与えている。

\section{（3）嫌気ろ床による有機物の低分子化}

BODの低減においては、嫌気性細菌の作用による有機 物の可溶化及び低分子化が進行するため、嫌気ろ床槽流 出水の BOD 及び比較対象実験施設の沈殿分離槽流出水 のBOD と揮発性低級脂肪酸（VFA）との関係をそれぞれ Fig. 8 に示した。

嫌気ろ床槽及び沈殿分離槽のいずれも BOD とVFA と の間には、次式で表される直線関係が得られ、同一VFA に対して沈殿分離槽流出水の方が高いBOD値を有する 傾向を示した。また先に述べたように、沈殿分離槽は嫌

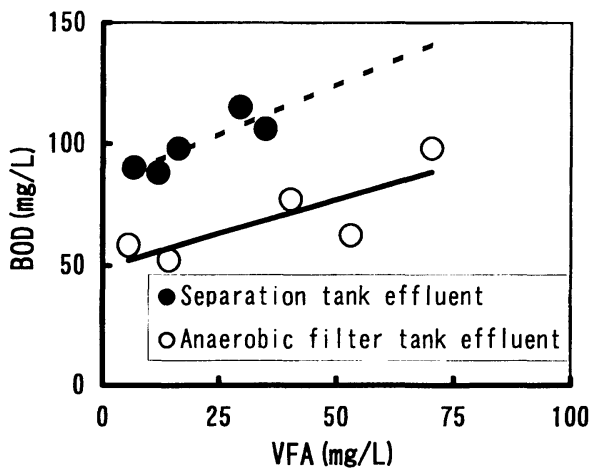

Fig. 8 BOD and VFA in the effluents of sedimentation/ separation tank and anaerobic filter tank
気ろ床槽流出水に比較してD-BOD BODが低いことか らも、有機物の低分子化は嫌気ろ床槽で進行しやすいこ とが認められた。

$$
\begin{array}{ll}
\text { 沈殿分離槽 } & \mathrm{BOD}_{1}=0.828 \mathrm{VFA}_{1}+83.0 \\
\text { 嫌気乃床槽 } \mathrm{BOD}_{2}=0.559 \mathrm{VFA}_{2}+48.9
\end{array}
$$

$\mathrm{BOD}_{1}$ ：沈殿分離槽流出 BOD濃度 (mg l $)$

$\mathrm{VFA}_{1}$ ：沈殿分離槽流出 VFA濃度 $\left(\mathrm{mgCH}_{3} \mathrm{COOH} l\right)$ $\mathrm{BOD}_{2}$ : 嫌気乃床槽流出BOD濃度 (mg l $l$ )

$\mathrm{VFA}_{2}$ ：嫌気乃床槽流出 VFA濃度 $\left(\mathrm{mgCH}_{3} \mathrm{COOH} l\right)$

したがって、槽内のSS捕捉性の高いろ材を充填するこ とにより、流入水中のSSがろ床内に捕捉され、同時に、 有機物がろ材表面に付着した嫌気性細菌によって低分子 化が進行するものと考えられる。

次いで、低分子化に及ほすBOD除去機能の影響を明確 にするため、実験期間中において嫌気ろ床槽によるBOD 除去率が $60 \%$ 以上を維持した場合と、そうでない場合と のVFAの成分比について検討を行った。

Fig. 9 は、代表的なVFAである酢酸、プロピオン酸、 酪酸、吉草酸、カプロン酸がVFAの総量に占める割合を それぞれ示したものである。嫌気ろ床槽において、BOD 除去率 $60 \%$ 以上が安定に維持されていた条件では、酢酸 $81.0 \%$ 及びプロピオン酸 $19.0 \%$ であり、酪酸〜カプロン 酸は検出されなかったが、BOD除去率が $60 \%$ 未満の場合 には、酪酸、吉草酸及びカプロン酸の占める割合が、VFA 総量の $11.9 \%$ を占めており、明らかな差が認められた。 同様に、比較対象実験槽の沈殿分離槽についても、VFA 総量に対する酪酸、吉草酸及びカプロン酸の占める割合 が10〜15\%となっていた。

これまで、し尿処理施設における嫌気性消化では、酸 発酵からメ夕ン発酵へ移行する際の基質として酢酸が主 であると報告されており、また分子量の高い脂肪酸が残 留しているとガス化が低下し、有機物の消化が不安定で あるといわれている ${ }^{17-19)}$ 。さらに、下水污泥の嫌気性消

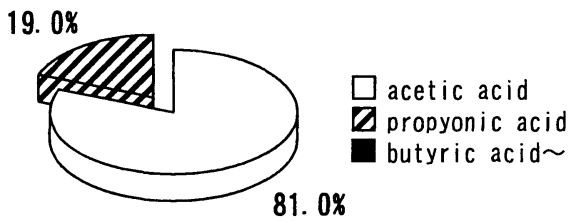

BOD removal $\geqq 60 \%$

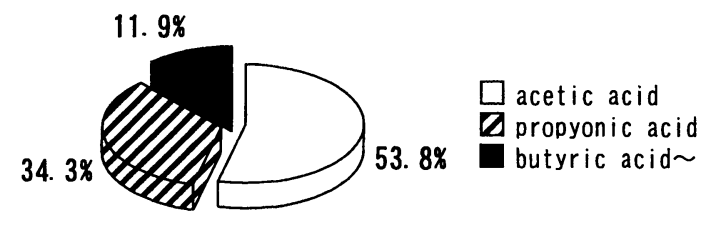

BOD removal $<60 \%$

Fig. 9 Component ratio of the VFA in anaerobic filter tank 
化では、低級脂肪酸が減少する場合、先に酢酸が低下し、 プロピオン酸は他の低級脂肪酸が低下を開始しても、し ばらく増加傾向を示すと報告されている ${ }^{20}$ 。

そこで、嫌気ろ床槽においても、VFAのうち、分子量 の高い酪酸、吉草酸あるいはカプロン酸が残留している 状況では、BOD除去率が低く、酸発酵からメタン発酵に 移行する率が低下していることが予測される。

合併処理浄化槽の場合、流入BOD濃度が200mg $l$ 前後 の比較的低濃度であり、し尿及び下水污泥の嫌気性消化 とは環境条件が異なっているが、VFAの主成分が酪酸以 上の分子量を有する低級脂肪酸の残留しない状況、すな わち、ろ材を充填することによるSSの捕捉性の強化、滞留 時間の確保により、有機物除去は容易であり、また後段 の好気性処理へのBOD負荷が低減されると考えられる。

\section{4. まとめ}

本研究では、嫌気ろ床槽のろ材の仕様と SS捕捉性の関 係を明らかにし、実際の戸建住宅に設置した小型合併処 理浄化槽による嫌気ろ床槽の実流入条件下での有機物除 去特性について検討した結果、次の知見が得られた。

1 ）嫌気ろ床槽第 1 室にピッチ $100 \mathrm{~mm} \times 70 \mathrm{~mm}$ の網様板 状、第 2 室に直径 $150 \mathrm{~mm}$ の骨格様球状ろ材を充填した 仕様が、最もSSの捕捉性が良好であった。

2 ）嫌気ろ床槽は、沈殿分離槽の $60 \%$ 程度の有効容量で あり、水理学的滞留時間も1.5日分であるが、ろ材のSS 捕捉及び有機物除去により平均BOD除去率は $67.9 \%$ であった。

3 ) 実施設においても嫌気ろ床槽のBOD除去反応は、人 工下水を用いた実験室レベルでの検討結果と同様に一 次反応で表され、見かけの比BOD除去速度恒数は 5.2 $\times 10^{-2} l$ h hrが得られた。

4 ）BOD とVFAとの間には高い相関が認められ、嫌気ろ 床槽は沈殿分離槽よりも低分子化が進行する状況であ った。

5 ) 嫌気乃床槽流出水中のVFAの構成成分は、主として 酢酸、プロピオン酸であったが、BOD除去率の低下し た条件では、さらに分子量の高い酪酸、吉草酸、カプ ロン酸が残留していた。

\section{参考文献}

1 ）小川浩：生活排水処理方法のしくみと種類、月刊下 水道、24(5)、10-14（2001）

2 ）金子光美、河村清史、中島淳編：生活排水処理シス
テム、技報堂、東京、4-22（1998）

3 ）環境省大臣官房廃育物・リサイクル対策部廃棄物対 策課浄化槽対策室：平成12年度浄化槽行政組織等調 査結果、環境省浄化槽対策室資料（2001）

4 ）建設省 (現国土交通省)：屎尿浄化槽の構造方法を定 める件、平成 12 年 5 月 31 日付き建設省告示第 1465 号 (2000)

5 ) 北尾高嶺：小型合併処理浄化槽の構造および維持管 理、財)日本環境整備教育センター、東京、64-72(1990)

6 ）建設省下水道部、厚生省水道環境部監修：下水試験 方法、(社)日本下水道協会（1997）

7 ）国安克彦、楊新泌、仁木圭三、久川和彦、大森英 昭：小型合併処理浄化槽の放流水BODの時間変動 特性、浄化槽研究、9(1)、13-26 (1997)

8 ）国安克彦、大森英昭、石原光偷、久川和彦、楠本正 康：生物膜法による小型污水処理施設の設計上の要 因、第 3 回生物膜法研究会講演要旨集、50-58(1983)

9 ）大久保卓也、細見正明、岡田光正、村上昭彦：嫌気 性ろ床法における外来懸濁物質蓄積の影響評価モデ ル、水環境学会誌、16(12)、50-63（1993）

10）北尾高領、木曽祥秋、笠井一次：嫌気一好気性乃床 システムによる污濁物質の除去機構とその数值解析、 下水道協会誌論文集、28(324)、17-27（1991）

11）建設省住宅局建築指導課等監修：屎尿浄化槽の構造 基準 · 同解説、財)日本建築センター、210-212(1996)

12）小川浩、大森英昭：コミュニティ・プラントにおけ る流入条件と処理機能の評価、浄化槽研究、13(1)、 29 (2001)

13）日本環境整備教育センター：昭和63年度厚生省委託 水環境を確保するための生活排水等の高度処理技術 の確立に関する研究報告書、9-11（1989）

14）北尾高嶺、木曽祥秋、金富吉：嫌気性接触沈殿法に よる生活排水の一次処理、浄化槽研究、2(1)、15-22 (1990)

15）稲森悠平、池谷正雄、岩堀恵祐、国安克彦、須藤隆 一：低濃度有機性排水の嫌気性ろ床処理に及ほすす温 度の影響に関する数理的解析、用水と廃水、25(10)、 34-42 (1983)

16）山本康次、中野仁、北尾高嶺、大森英昭、藤井正 博：嫌気性ろ床を用いた家庭下水の処理、下水道協 会誌、22(255)、12-22（1985）

17) Hans Weber, Klaus D. Kulbe, Horst Chmiel, and Walter Trosch: Microbial acetate conversion to methane :kinetics yields and pathways in a two-step digesion, Applied Microbiology and Biotechnology, 19, 224-228(1984)

18）長坂實上、荒又健夫、佐藤義典、佐川季男：消化槽 の初期運転について一揮発性有機酸の濃度変化一、 第21回下水道研究発表会講演集、508-510（1984）

19）浦辺真郎、寺島泰：廃棄物を用いた嫌気性消化に関 する基礎的研究、水処理技術、25(6)、9-19（1984）

20）岡田和男編：下水污泥の処理 ·処分、環境公害新聞 社、東京、133-162（1982）

（受付 2001.10.10)

（受理２001.12.28） 